\title{
The relationship between organizational environment antecedents and performance management in local government: evidence from Ghana
}

\author{
Juliana Abagsonema Abane ${ }^{1 *}\left(10\right.$ and Edward Brenya ${ }^{2}$
}

\begin{abstract}
The study aimed to investigate the relationship between organizational environment antecedents and their impact on performance management among local government authorities and to further understand the role of the stakeholder and political support in the performance monitoring and review of local governments. The study used quantitative research design techniques in the data collection phase between May and August 2017 in the Greater Accra Region of Ghana. The sample included 850 middle level and senior managers of the Local Government Service. Multiple regression was used to analyze the data. The results of the findings indicate that there is a strong relationship between two organizational environment variables: "stakeholder participation", political support, and performance management providing a variance of 31.8 percent of the changes in the dependent variable. However, the findings further suggest that stakeholder participation was a better predictor of performance management than political support. Additionally, employees' age, gender, and organizational size were statistically significant in the model fit. This study is one of the first of its kind to link two organizational environment indicators (stakeholder support and political support) and their effect on two performance management dimensions (performance monitoring and evaluation, and performance review). Also, few studies have used the structural contingency theory in explaining the influence of the environment on internal business processes of organizations in the performance management literature.
\end{abstract}

Keywords: Local government, Organizational environment antecedents, Performance management, Political support, Structural contingency theory

\section{Introduction}

Ghana implemented its performance management (PM) policy at the local level in 2012 followed by the firstever performance evaluation assessment conducted in 2015 for all the 216 metropolitan, municipal, and district assemblies (MMDAs) in the country [1]. Abane and Phinaitrup's study observed that stakeholder participation was absent and that affected MMDAs performance. As a result, the current study sought to investigate two

\footnotetext{
*Correspondence: abanejulie@gmail.com

${ }^{1}$ University of Mines and Technology, Tarkwa, Ghana

Full list of author information is available at the end of the article
}

organizational environmental variables: stakeholder participation and political support, and their impact on the PM of local governments (LGs) in Ghana.

The purpose of studying these two organizational environment variables is to further validate the findings on the contributions of the environment to PM at the local level because the local environment of LGs is different from the macro-environment which should be an issue of concern to local actors and the central government in general. More specifically, Ghana was selected because of its role that it plays in the sub-region as the gateway to Africa and under the New Partnership for Africa's Development (NEPAD) which mandates African governments 
to develop strategic frameworks to manage their development efforts and eradicate poverty at both the national and local levels to ensure sustainable development [59]. It is based on this background that the country since 2012 has implemented several change management strategies to achieve local-level performance. This study draws on this innovation that seeks to achieve high performance at the local level and make a contribution to the literature by providing empirical support of the influence of the organizational environment on the change management programs instituted at the MMDAs level in the country.

The link between organizational environment antecedents and PM is inconclusive [10,63]. According to Yang and Hsieh [63], they found that the influence of political support and stakeholder involvement on PM effectiveness was positive yet not statistically significant. However, Moynihan and Pandey [39] found that citizen participation had an effect size of $10 \%$ confidence level $(p=0.062)$ on PM data used in decision making. Organizational environment antecedents refer to the fit between the internal and external environment of the organization that conventionally affects the internal business process of organizations. This is because PM is conceived as an internal business process designed to achieve the mission and objectives of organizations $[9,43]$.

According to Moynihan and Pandey [38], PM is "a system that generates performance data through strategic planning, performance measurement routines and connects the data to decision venues, where, ideally, the information influences a range of possible decisions" (p. 5). Also, Gerrish identifies seven elements of a PM that includes a set or a bundle of practices and activities that organizations engage in. The elements are the setting of performance goals, performance rewards, collecting information and feedback, benchmarking and monitoring, and budgeting. However, these best practices are both "theoretical and how-to-do list than a definition" [23, p. 8].

On the importance of PM and performance, there are vast scholarly works that seek to anchor its relevance in the performance literature $[28,29,41]$. At the same time. PM has been described as a developmental that provides organizations the opportunity to tailor their training to specific areas of employee task performance skill-gap [1, 4 , 35] PM effectiveness is also linked to several factors that enhance its importance in the public sector. Factors such as quality of goals [33], measurement, and performance improvement [57]. However, little attempts have been made to discuss the influence of the organizational environment on PM at the district level-management.

The effect of the organizational environment has been studied with few studies providing evidence on the variable. For example, Bouckaert and Halligan found that countries with solid performance culture and those with a political crisis, do have positive results on their PM policies than those in transitional democracies [56]. However, evidence suggests that other organizational environment variables such as political support, organization culture, and stakeholder participation offer inconclusive evidence that calls for further studies to validate previous findings [52, 63].

PM is not a new concept and its research has been around for the past two decades [11, 14, 61]. PM may include, regular performance meetings or reviews [40], goal-orientation, and resource allocation [17], training, and performance improvement $[17,18]$. Contributing to the discussion, Gerrish [23] used a meta-analysis and identified four variables that are important to PM research: best practices, second-generation PM systems, effect size, and the context of the study. Based on the aforementioned, this study conceptualizes PM to include two practices of organizations, performance monitoring and evaluation, and performance review. The paper is organized into six sections. The first part introduces the paper, followed by the literature review, the methodology, the results, and discussions. The last section concludes the study.

\section{Performance management best practices}

PM best practices refer to the design, implementation, and adoption of performance targets for desired organizational outcomes [7, 21, 48]. Performance management best practices involve the setting of goals, goal-alignment, monitoring progress, providing feedback, and review of employees' targets. Various frameworks seek to explain the best PM practices [7, 31]. Kroll et al. [30] argue that PM best practices include strategic planning, feedback, and improvement while, Kaplan and Norton's [29] balanced scorecard (BSC) framework was developed to allow organizations to include their vision, mission, and strategy into action during the design phase of the PM policy. The BSC provide organizations to include a feedback mechanism to monitor their progress both from the internal and external environment. In this framework, the authors focused on only four attributes, "customer-oriented quality service", "financial accountability", "internal efficiencies", and "organizational learning". Though this model is widely used to study PM best practices, it is mainly a single-loop approach to PM [20, 30].

The public sector scorecard (PSS) seeks to include as a best practice by focusing on the fit between the values and the context of public institutions. The PSS adds financial value as an outcome-based approach to stakeholder value maximization, yet emphasizes the following values: risk management, organizational culture, 
inter-sectoral collaborations, performance, and service improvement as key indicators of a PM policy.

Also, Otley's [48] framework discusses five important questions of organizations that serve as best practices of PM. Otley's framework focuses on the central issues which contribute to the fit between the four major practices of PM, thus objectives, strategic planning, target-setting, incentive and rewards structures, and information feedback loops. The model also extends the BSC and emphasizes organizational performance, value-formoney, and the developmental approach to PM. The author further explains that how these practices are monitored and evaluated can be a critical success factor for PM reforms. The framework emphasizes the importance of the feedback process which must focus on 'feedback and feed-forward loops' to enable the organization to learn from its experience and to adapt to its current behavior [48, p. 366]. The feedback mechanism or review process is supposed to be linked to employees' learning, empowerment, and organizational strategy through the strategic planning process. The focal point for organizations is to receive feedback to ensure that they learn from both individual and organizational performance to enable them to develop emergent strategies that can support growth and results-based performance.

The framework focuses on strategic planning, feedback loops or review, evaluation, and performance improvement. These four areas of the framework are closely linked to each other and several empirical studies have explored these practices in public organizations. However, few studies have studied these practices at the local government (LG) level.

Based on Otley's [48] model, PM best practices can be conceptualized to include four major bundles of practices strategic planning, performance monitoring and evaluation, performance review, and performance improvement. However, this study only considers performance monitoring and evaluation and performance review to constitute the bundle of best practices of PM of LGs which will help to answer the research hypotheses. Table 1 describes the dimensions of PM best practices.

\section{Structural contingency theory}

This study appeals to the structural contingency theory (SCT) because the environment is a core variable of this theory and it explains why some processes of PM are influenced by external forces of LGs PM policies. The SCT emphasizes a "fit between structure and design parameters that leads to organizational effectiveness and performance" [36]. The theory assumes that there is "no one best way" to organize and that "different ways of organizing is not equally effective" [22, p. 2, 51].

Further, the theory presupposes that the design of an organization depends on different contingent factors like age, size, technology, environment, and power that explain why some organizations perform better than others [37]. Moreover, the SCT views organizational performance as a fit between the contingency variables and structure. However, mismatch arises if these factors are not addressed [22, 26, 36]. SCT implies that managers have an "efficiency-seeking" culture that produces fit between internal business processes and the contingency factors.

Empirically, evidence of the three dominant SCT variables: size, technology, and the environment are widespread in the literature. For example, the Weberian variables focus on the size of the administrative component, the degree of centralization, formalization, the level of differentiation, the extent of task specialization, and vertical elaboration impacts on organizational effectiveness [51, p. 148].

Further, among the three variables above, organization size is most widely researched in the PM literature $[43,58]$. Size as a contingent variable is attributed to Max

Table 1 Summary of the dimensions of PM

\begin{tabular}{|c|c|c|c|}
\hline No. & Variable & Definition & source \\
\hline 1. & Strategic planning & $\begin{array}{l}\text { Strategic planning refers to the development of mission, vision, values, and } \\
\text { the criteria for measuring organizational outcomes its achievement }\end{array}$ & Ammons and Roenigk [3] \\
\hline 2. & Performance monitoring and evaluation & $\begin{array}{l}\text { Performance monitoring and evaluation is the process of tracing and } \\
\text { setting benchmarks for measuring and ranking employee performance } \\
\text { targets. It also involves meetings with the assessor and the assesse to } \\
\text { agree on the targets and their outcomes } \\
\text { Performance evaluation also takes the form of formal appraisal of employ- } \\
\text { ees in a performance year }\end{array}$ & Lee [34] and Otley [48] \\
\hline 3. & Performance review & $\begin{array}{l}\text { A performance review is a process where employees get to know how they } \\
\text { have been able to achieve their targets or goals }\end{array}$ & Biron et al. [7] \\
\hline 4. & Performance improvement & $\begin{array}{l}\text { Performance improvement is the process of obtaining formal information } \\
\text { on the performance targets to help employees to correct performance } \\
\text { deficiencies and enhance future performance }\end{array}$ & Lee [34] \\
\hline
\end{tabular}


Weber in which he argued that bureaucracy is more profound in large organizations than in smaller organizations [62]. Others such as Pugh et al. [54] find that size is the most predictor of specialization, the use of procedures, and the reliance on paperwork. Blau [8] further notes that size results in structural differentiation in organizations. However, differentiation decreases as size increases [51, p. 149].

\section{Empirical review of structural contingency variables}

Organizational Environment antecedents refer to both the external and internal processes and administrative procedures of organizations, which affects the PM adoption $[48,63]$. Earlier research showed that different environmental conditions result in different organizational structures [12]. Burns and Stalk found that a bureaucratic organizational structure is suitable for a stable and certain environment while an organic structure, is relevant in a dynamic environment. However, environmental uncertainty has been widely studied while political structures and stakeholder involvement have received less attention in the PM literature $[10,52,63]$.

Also, previous studies on the relationship between contingency factors and PM found a link between organizational culture, internal business processes, and PM effectiveness $[43,58]$. Adding to this view, Bouckaert and Halligan [10] in their study observed that the PM system of countries was sharply different because of the level of political and multi-stakeholder influences.

Political Support: Political support denotes the authority and autonomy of an agency given by political actors to implement policy decisions [63]. It also connotes the degree of support offered an organization by elected officials by releasing more resources for program intervention and policy implementation. According to Pollitt and Bouckaert [52] and Yang and Hsieh [63], political support has a positive relationship with PM effectiveness. This is because a good political environment motivates administrators and managers, which will affect resource allocation and funds to support PM activities.

Political support for public sector performance reforms in countries like Norway, New Zealand, Finland, and France has proven to be successful in the new public management (NPM) reforms $[15,25]$ because of regime support. Public institutions with political support have more autonomy, power, and resources to implement and adopt PM policies to achieve their goals. Politicians may influence the vision, values, strategies, and goals of the reform agenda and their commitment will help to clarify the missions and values of PM goals.

While there is little evidence on how political leaders adopt this role in the PM process, research has shown that political support is likely to increase the achievement of the mission, goals and lead to adequate allocation of resources to support PM systems [27]. However, political support may be at the rhetoric level rather than practice. For instance, politicians are quick to offer and proclaim what needs to be done in the face of reforms, but their level of commitment to the implementation processes is less effective [52]. In most cases, politicians do want to share the responsibility of policy failures with public managers by intentionally setting vague goals instead of clear and specific policy objectives [33].

Despite the evidence from these findings, others argue that political leadership interferes with agencies' performance in some instances and the need to separate politics from administration in public institutions. Many political systems have different political actors with different interests which may lead to uncertain behavior and reasonable risk-taking and lack of flexibility on the part of public managers [60]. Political approval of policy goals has unintended consequences on performance; however, Rainey and Steinbauer [55] argued that public organizations can mobilize the support of elected officials to achieve the mission of the organization. In this study, political support refers to authority, the autonomy of an agency, and the support of elected officials for an agency's PM process [63]. The model of political support given by Yang and Hsieh [63] is revised to include the timely allocation of resources for implementing PM policies. Figure 1 depicts a POLSP framework.

"Stakeholder Participation": Stakeholder participation means the involvement of key actors in the PM process. Stakeholders include elected officials, political executives, administrative, professional, and operational staff, and citizens/customers [10].

Internal and external stakeholders are critical to PM goals [63]. Yang and Hsieh [63] found that participation affects the formulation and adoption of performance measurement outcomes. The authors further observed that general stakeholder participation influences the effectiveness of PM systems while external stakeholder participation reported a significant impact on the formulation and adoption of PM policies in countries like Taiwan [63].

Similarly, a study of public managers in Taipei involving 684 respondents, found that stakeholder participation had a mean value of 14.72 and a standard deviation of 4.22 which was lower than the other variables indicating little support for the variable. The implication for the mean in the study sample suggests that stakeholder participation had little influence on PM effectiveness. However, the structural equation model (SEM) used to test the fit of the theoretical model revealed that all the variables including stakeholder participation had a significant influence on PM effectiveness. The study also found that 


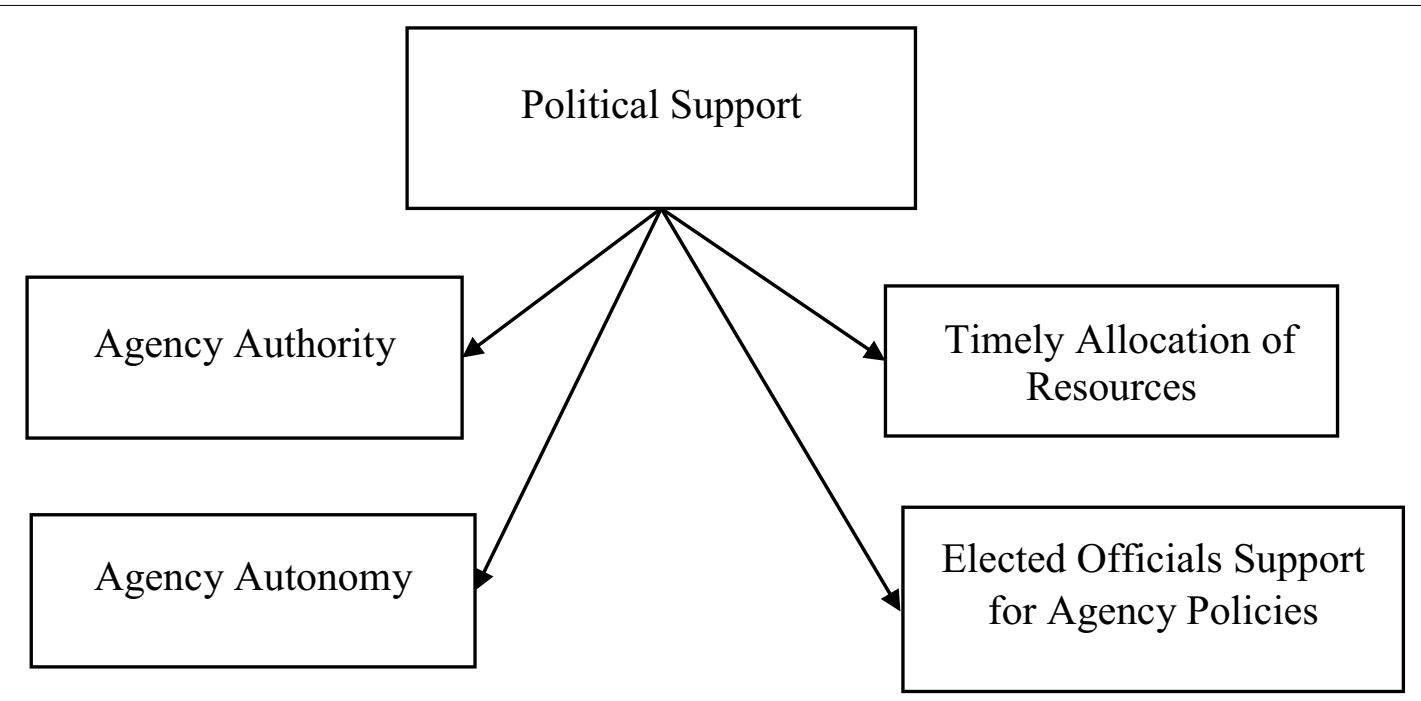

Fig. 1 Indicators of political support. Source: Modified from Yang and Hsieh [63]

agencies that involved political actors or legislators in the PM process improved PM outcomes than those who did not involve any kind of stakeholders.

Conaty [16] found that multi-stakeholder participation in the PM process has an impact on its effectiveness. The multi-stakeholder framework used showed that five organizational attributes, inter-stakeholder relationships, tension over objectives, culture, institutional clashes, and power distribution had an impact on PM. In this study, stakeholder participation refers to elected officials and appointed executives, employees, and citizens/ customers.

\section{The relationship between organizational environment antecedents and PM}

Mintzberg [36] and Oliver [47] argue that the environment of organizations is affected by a constant change in which managers must adapt speedy mechanisms to contain the external forces. Therefore, whether there is low support for stakeholder participation and political support or not, the environment is undeniably a strong inertia force that can have an impact on the PM process positively or negatively. This is consistent with a study of seven countries namely; Brazil, Ghana, Indonesia, Ireland, Italy, Portugal, and Spain [56] which found that PM has better outcomes in politically unstable countries and well-establish administrative culture than countries with young democratic governance. This implies that in countries where managerial support is high, it leads to better results.

Political commitment correlates with PM because of the uncertainty and the ability of political leadership to motivate administrators and managers during performance evaluation and review processes [38, 52, 63]. Yang and Hsieh [63] found that political support leads to autonomy, authority, and support for an agency's annual performance review programs by elected officials. Also, political support is needed because it allows senior public managers the freedom to act and be responsible for their choices in the PM process. However, Yang and Hsieh's study failed to link political support with resource allocation for implementing PM policies. This is because the perceived support of politicians will lead to more allocation of resources and funds to support PM activities that perhaps affect the study's findings on the variable. External political support is important because of the cost of developing and implementing a PM system that is related to tangible resources and technical competencies. The following hypotheses will guide the study:

$H_{1}$ There is a positive and significant impact of organizational environment antecedents on the PM of LGs.

$\mathrm{H}_{2}$ There is a positive relationship between political support and PM and its indicators.

$\mathrm{H}_{3} \quad$ Stakeholder participation has a positive and significant effect on PM and its sub-indicators.

\section{Methods/experimental}

The context of performance management in Ghana

Generally, PM has been reported to have different effects under different governments and context. These seeming difficulties encountered by governments globally are not unique in the Ghanaian experience. Ghana is one of the 
West African countries to have obtained independence from the British colonial administration in 1957. Since independence, the country has largely remained a unitary state with a presidential system of government-run by three arms of government: the executive, legislature, and the judiciary. However, the executive arm of government constitutes the administrative system in charge of implementing policies and projects under the civil service and the public service in particular $[5,44]$.

In terms of human capital development index, the country is under the category of a medium Human Development Index (HDI) which suggests that a minimal level of trust in governments while there is still a widening gap in inequalities in terms of social services and economic inclusiveness [59]. However, Ghana is ranked as one of the best HDI in sub-Saharan Africa with a 0.596 value for 2018. The implication is that the country has a sizeable number of human resources needed for economic growth and development compared to her neighboring countries within the sub-region. Despite being a medium HDI, the country continues to implement performance reforms in the public sector to ensure a good provision of social services to the citizens especially at both the national and local-level governance the 1970s [53]. Some of the PM reforms were introduced during the Structural Adjustment Programme (SAP) and the Economic Recovery Programme (ERP) era. The first reform program under the SAP was to improve performance within the civil service, popularly called the Civil Service Reform Program (CSRP). However, the report suggests that the goals of this reform program failed to achieve the desired impact due to poor performance culture in public organizations [46]. One of the reasons for the failure of this reform has been reported to be the weak administrative culture of the civil service [46].

Another program under the autopsies of the Civil Service Performance Improvement Program (CSPIP) also fell below reasonable expectations to achieve high performance from civil servants [45]. The CSPIP was designed to improve service delivery, a performance culture, and results-driven towards attaining value for money, accountability, transparency, customer satisfaction, as well as efficiency and effectiveness of the public service [45]. The CSPIP though the first of its kind to institutionalized performance-driven culture in the Ghanaian public service which was comparable to other developed countries PM systems, was set out to fail due to implementation challenges [2]. The CSPIP had among other features, development, and signing of performance agreements and contracts between the government and senior managers such as chief directors of various ministries, departments, and agencies (MDAs) [45]. Even though it was a major attempt to implement PM reform, the CSPIP reform initiative failed to deliver on its objectives and the implementation outcomes were far below reasonable expectations of the civil service and public service delivery in general [2].

Subsequently, in 2012, the government of Ghana decided to implement a PM system in the public service and in particular the Local Government Service which sought to institute PM in the country to improve performance and service delivery [1]. The new policy considered stakeholder participation because the framers felt that the environment of organizations is important determinants in policy outcomes. Hence, wider stakeholder consultation with key political actors and public managers is one of the implementation strategies in the development of public institutions' performance targets. Despite the depth of information on the new PM policy in the country, little empirical evidence exists to assess the role of the organizational environment antecedents and their impact on PM outcomes.

\section{Sample participants}

The sample frame in the study consist of 1,849 local government sector employees in the Greater Accra region who were below the grade of deputy director (DD) (Level 21), which included Assistant Director I (Level 19) to Senior Executive (Level 15), and the equivalent grades in the region. Grades that were below DD are Level 19, 18,16 , and 15 which are termed middle-management level in this study. Therefore, grades that fall below this category were not be included in the study because the focus of the study was to understand the nexus between PM and organizational environment antecedents from the perspectives of middle management. The study adopted a quantitative research method because this type of approach is widely used in empirical investigations in behavioral sciences.

After establishing the sample frame, a pilot study of 50 questionnaires was administered in April 2017. Pretesting of the survey instrument was to allow the researcher to test for the suitability of the questions and determine the understanding of the questions by the respondents as well as observe respondents' interest and feedback on the questionnaires. The responses were analyze using the Cronbach alpha of the individual scales which was found to be reliable since similar instruments in previous studies yielded an alpha of 0.7 and above. However, corrections were made before the final distribution of the questionnaires in May 2017. The reason for choosing to pretest the survey instrument was because the scales and constructs used in this study were borrowed from previous studies that were carried out in different settings. And because contextual factors are important in defining a country's PM model, pilot testing of the various adapted 
scales allowed for the selection of those items that strictly defined the context of the study.

\section{Survey administration}

The study used a cross-sectional quantitative research method because this type of approach is widely used in empirical investigations in behavioral sciences, most especially because of the availability of the participants since it is much easier to collect data at one point in time rather than a longitudinal design. Also, the quantitative method allowed for the testing of the hypotheses by using correlations and regression analysis. The study was conducted in Ghana between May and August 2017 involving 850 local government managers in eleven (11) MMAs in the National capital, Accra. These employees were senior middle-level managers' comprising administrative officers and their equivalent grades in the Local Government Service (LGS). Ghana has 260 local government authorities in 16 administrative regions, which are responsible for the management and implementation of the government's policies and programs. The purpose of choosing the Greater Accra Region and the eleven (11) MMAs was informed by the performance evaluation results of the LGS annual performance monitoring in 2015 [1]. Out of the 850 questionnaires administered, 655 were completed and received providing a $77.0 \%$ response rate.

\section{Procedure and measures}

The major sources of the questionnaires were drawn from previously developed measures. However, a few modifications were made to suit the context of the study. For instance, the questionnaires for the PM scale and the two organizational environment antecedents were adapted from Yang and Hsieh's [63] and Gianakis and Wang [24]. The dependent variable was conceptualized to include two (2) main dimensions, PME, and PEREV (see Table 12 in Appendix 1 for details). PME had five (5) items and PEREV had three (8) items that were adapted from Dewettinck and van Djik's [19], Mohamad and Ismail [42], and Yang and Hsieh's [63] studies. For the independent variables, the questionnaires were made up of eleven (11) items measuring STAKHOP, and eight (8) items measured POLSP excluding respondents' demographics (see Table 13 in Appendix 2). A 7-Likert-item scale was used. The scale was treated as an interval-level scale which is not new since previous studies used the same procedures with Likert-items $[6,32,50]$. The Likert-item asked the respondents to indicate their level of agreement or disagreement on the questions (see Table 2). The interpretation of the scale was scored by using 7-5 for agreement while 4,2 , and 1 were interpreted as disagreement while 4 was considered indifferent.

\section{Reliability test}

The reliability results suggest that the individual scales are robust for each item. Table 3 shows the variables and their Cronbach Alpha for both individual and combined scales. For the dependent variable subscales, the highest was PEREV $(\propto=0.86)$ followed by PME $(\alpha=0.83)$. Additionally, the total scale for PM is $\propto=0.90$. The independent variables, STAKHOP had $\mathrm{a} \propto=0.88$, while POLSP scored $\propto=0.73$ and the combined scale (ORGENANTE) had $\mathrm{a} \propto=0.87$ (see Table 3 ).

\section{Control variables}

Control variables are variables that may affect the internal validity of the findings if they are not held constant. The study had layers and employees with different grades, years of experience, and educational qualifications that may affect their responses and their knowledge of the questions under investigation [58]. Additionally, studies such as Cavalluzzo and Ittner [13] and Moynihan

Table 3 Summary results of reliability test

\begin{tabular}{llll}
\hline Variable & $\begin{array}{l}\text { Cronbach alpha } \\
(\mathbf{a})\end{array}$ & No. of items & $\boldsymbol{N}$ \\
\hline PME (PM1) & 0.83 & 5 & 437 \\
PEREV (PM2) & 0.86 & 8 & 436 \\
PM (PME + PEREV) & 0.90 & 13 & 432 \\
STAKHOP & 0.88 & 11 & 433 \\
POLSP & 0.73 & 7 & 441 \\
ORGENANTE (STAK- & 0.87 & 18 & 433 \\
HOP + POLSP) & & & \\
\hline
\end{tabular}

Table 2 Survey instrument format

\begin{tabular}{|c|c|c|c|c|}
\hline Section & Measure & Sub-measure & Items & Response pattern/score \\
\hline A & Performance management (PM) & $\begin{array}{l}\text { Performance Monitoring and Evaluation (PME) } \\
\text { Performance review (PEREV) }\end{array}$ & $\begin{array}{l}5 \\
8\end{array}$ & $\begin{array}{l}\text { Strongly agree }=7 \\
\text { Strongly disagree }=1\end{array}$ \\
\hline B & $\begin{array}{l}\text { Organizational environment ante- } \\
\text { cedents (ORGENANTE) }\end{array}$ & $\begin{array}{l}\text { Stakeholder participation (STAKOP) } \\
\text { Political support (POLSP) }\end{array}$ & $\begin{array}{r}11 \\
8\end{array}$ & $\begin{array}{l}\text { Strongly agree }=7 \\
\text { Strongly disagree }=1\end{array}$ \\
\hline C & Control variables & $\begin{array}{l}\text { "Age group, Assembly size, gender, grade, educa- } \\
\text { tion and experience }\end{array}$ & & Multiple choice questions and yes/no \\
\hline
\end{tabular}


and Pandey [39] have found a significant relationship between employee position in an organization and their level of awareness of the measurement system.

The results showed that the average of the age group is 20-39 years $(43.1 \%)$ with a mean score of 3.0 and an $\mathrm{SD}=1.01$. Also, $59.6 \%$ were males and $40.4 \%$ were females. The highest level of education was a bachelor's degree $(56.7 \%)$, with a mean score of $2.18, \mathrm{SD}=0.977$. Also, $68.0 \%$ were employees from municipal assemblies while Metropolitan assembly employees were $32.0 \%$ representing size since the latter is bigger than the former. Additionally, for the experience variable, $59.0 \%$ of the respondents had between 1 and 5 years of working experience from the first entry. Further, the grade of respondents, showed that $69.6 \%$ were administrative officers.

\section{Results and discussion}

The data analytic tools employed for this study were a series of multiple regressions and ANOVA. The ANOVA was used because the sample was from two independent sample groups: metropolitan and municipal assemblies to observed the differences in their means across the dataset. The procedure for analysis of the variables started by exploring the data to ensure that, the data meets the multiple regression assumptions. A multicollinearity test was performed and the results showed that all the variables in this study had a correlation matrix lower than 0.70 which is accepted in social science research [49]. The standard multiple regression methods were used while control variables were introduced to determine whether the two independent variables had an impact on the dependent variable $(\mathrm{PM})$.

\section{Descriptive results}

Except for the POLSP which had 4.24 mean and $\mathrm{SD}=1.06$ indicating that the majority of the respondents 'slightly disagreed' with the Likert items for that variable, the results showed moderate support for the variables (see Table 4).

In Table 4, the individual scales for the variables were collapsed to form the PM variable (PME \& PEREV) and the ORGENANTE variable (STAKHOP \& POLSP).

\section{Table 4 Descriptive statistics}

\begin{tabular}{lccccc}
\hline Variable & Mean & Median & SD & Minimum & Maximum \\
\hline PME & 5.60 & 5.80 & 1.04 & 1.00 & 7.00 \\
PEREV & 5.04 & 5.25 & 1.15 & 1.00 & 7.00 \\
PM (PME+PEREV) & 5.25 & 5.53 & 1.00 & 1.51 & 7.00 \\
STAKHOP & 5.02 & 4.91 & 1.09 & 1.00 & 7.00 \\
POLSP & 4.24 & 4.14 & 1.06 & 1.00 & 7.00 \\
ORGENVIRONANTE & 5.03 & 4.50 & 0.91 & 1.18 & 7.00 \\
$\quad$ (STAKHOP + POLSP) & & & & & \\
Valid N (Listwise) 424 & & & & & \\
\hline
\end{tabular}

The results equally showed that respondents slightly agreed with the influence of the organizational environment antecedents providing 5.03 mean and $\mathrm{SD}=0.91$ while moderate support for the PM gave 5.25 mean and $\mathrm{SD}=1.00$.

\section{Bivariate analysis}

This section is used to run the correlation analysis to determine the relationship between the variables. Multiple regression assumptions were used to check violations of multicollinearity, linearity, independence of the sample, and homoscedasticity of the data. The listwise method option provided $N=424$ which is in line with the recommended $N>50+6$ m method [55]. PM is treated as a single dependent variable in the main model, which consists of two (2) indicators (PME \& PEREV). While the organizational environment antecedents (STAKHOP \& POLSP) were treated as a single independent variable to run the main model. However, all four sub-measures were run individually first before the main model.

Table 5, the results show significant and positive relationships between the independent variables and the dependent variable(s). For example, the relationship between PME and PEREV is 0.68 which is significant at $1 \%(p<0.01)$, while the correlations between STAKHOP and POLSP are $0.41, p=0.01$ (see Table 5).

Table 6 shows the bivariate relationship between the main variables: PM and ORGENANTE. The results suggest that there is a significant and positive relationship with $r=0.48$ and $p=0.01$.

\section{Regression results}

The results for the regression was run to test the hypotheses as well as observe the impact of the ORGENANTE on the dependent variable (PM) and its sub-measures. The analysis used standard regression methods and the second part of the analysis controlled for the influence of age, sex, experience, grade, assembly size, and education. An examination of the results for the controlled model and the standard methods did not show any significant

\begin{tabular}{llllll}
$\begin{array}{l}\text { Table } 5 \\
\text { of } \text { Corganizational environment antecedents and PM }\end{array}$ & \multicolumn{2}{c}{$\begin{array}{c}\text { matrix } \\
\text { of }\end{array}$} \\
\hline SN & Variable & $\mathbf{1}$ & $\mathbf{2}$ & $\mathbf{3}$ & $\mathbf{4}$ \\
\hline 1 & PME & 1 & & & \\
2 & PEREV & $0.681^{* *}$ & 1 & & \\
3 & STAKHOP & $0.451^{* *}$ & $0.489^{* *}$ & 1 & \\
4 & POLSP & $0.219^{* *}$ & $0.348^{* *}$ & $0.407^{* *}$ & 1 \\
\hline
\end{tabular}

STAKHOP stakeholder participation, POLSP political support, PME performance monitoring and evaluation, PEREV performance review

${ }^{* *}$ Correlation is significant at 0.01 ( 2 tailed); $N=424$ 
Table 6 Correlation matrix of organizational environment antecedents and PM

\begin{tabular}{llll}
\hline SN & Variable & $\mathbf{1}$ & $\mathbf{2}$ \\
\hline 1 & ORGENANTE & 1 & \\
2 & PM & $0.477^{* *}$ & 1 \\
\hline
\end{tabular}

ORGENANTE organizational environment antecedents, $P M$ performance management

** Correlation is significant at 0.01 ( 2 tailed); $\mathrm{N}=424$

difference. Hence the decision was made to present, only the models with control variables since the literature recommended holding size and age constant in testing the organizational environment antecedents [63]. The regression analysis depicts a positive and statistically significant effect of the independent variable on the dependent variable. The first regression model was run for the sub-measures of ORGENANTE: STAKHOP and POLSP to test the effect of their strength on the two PM submeasures: PME and PEREV. The second regression was performed to test the effect of STAKHOP and POLSP on $\mathrm{PM}$ as a single variable and the third model tested the effect of the variable 'ORGENANTE' (the combined strength of STAKHOP and POLSP) on PM.

\section{Regression Model 1(a) with PME as a dependent variable}

The results for the two independent variables suggest that the variables were able to provide $20.8 \%\left(R^{2}=0.208\right)$ to explain the variance in the dependent variable: PME when no control variable was introduced (see Table 7). Table 7 further shows that the second model depicting only STAKHOP showed that the effect size was reduced by 0.001 units when POLSP was absent in the model while the model improved by 0.082 units $(29.0 \%)$ when the control variables were included in the third model.

The hypothesized relationships in the first model suggest that the two variables: STAKHOP and POLSP, were statistically significant with $F(2,419)=55.172, p=0.000$. However, the Beta values showed that STAKHOP contributed more to the variance in $\operatorname{PME}(r=0.438, n)$ while POLSP contributed less $(r=0.042, n s)$. Also, the second model showed that the hypothesized relationship between the two variables (STAKHOP and PME) indicates a strong relationship with $F(1,420)=109.627$, $p=0.000$, the Beta value of $(r=0.455, n)$ and the variance for the model is $20.7 \%$. The third model summary for this hypothesis showed that the variance explained when the control variables were introduced, is $29.0 \%$ with a $F(7,414)=24.146, p=0.000$, and STAKHOP having $(r=0.452, n)$, age $(r=0.262, n)$, sex $(r=0.136, n)$, education $(r=-0.002, \mathrm{~ns})$, assembly size $(r=0.117, n)$, experience $(r=-0.123, n s)$, and grade $(r=-0.078, n)$ at $10 \%$ significant level (see Table 7). Except for education,
Table 7 Regression results with PME as a dependent variable

\begin{tabular}{|c|c|c|c|c|c|}
\hline Model & B & T-STAT & $\begin{array}{l}p \\
\text { value }\end{array}$ & $\begin{array}{l}\text { Summary } \\
\text { statistics }\end{array}$ & Prediction \\
\hline 1 & & & & $R=0.457$ & \\
\hline (Constant) & 3.358 & 14.343 & 0.000 & $R^{2}=0.208$ & \\
\hline STAKHOP & 0.438 & 9.230 & 0.000 & $\begin{array}{l}\text { Adjusted } \\
\qquad R^{2}=0.204\end{array}$ & \\
\hline \multirow[t]{3}{*}{ POLSP } & 0.042 & 0.881 & 0.379 & S.E. $=0.93836$ & \\
\hline & & & & F stat $=55.172$ & \\
\hline & & & & $p$ value $=0.000$ & \\
\hline \multicolumn{6}{|c|}{ 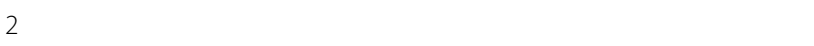 } \\
\hline (Constant) & 3.456 & 16.802 & 0.000 & $R=0.455$ & \\
\hline \multirow[t]{5}{*}{ STAKHOP } & 0.455 & 10.470 & 0.000 & $R^{2}=0.207$ & \\
\hline & & & & $\begin{array}{l}\text { Adjusted } \\
\qquad R^{2}=0.205\end{array}$ & \\
\hline & & & & S.E. $=0.93811$ & \\
\hline & & & & F stat $=109.627$ & \\
\hline & & & & $p$ value $=0.000$ & \\
\hline \multicolumn{6}{|l|}{3} \\
\hline (Constant) & 2.174 & 6.763 & 30.000 & $R=0.538$ & \\
\hline STAKHOP & 0.452 & 10.870 & 0.000 & $R^{2}=0.290$ & \\
\hline Age range & 0.262 & 4.766 & 50.000 & $\begin{array}{l}\text { Adjusted } \\
\qquad R^{2}=0.278\end{array}$ & \\
\hline Sex & 0.136 & 3.242 & 20.001 & S.E. $=0.89413$ & \\
\hline Education & -0.002 & -0.048 & 0.962 & F stat $=24.146$ & \\
\hline $\begin{array}{l}\text { Assembly } \\
\text { size }\end{array}$ & 0.117 & 2.780 & 0.006 & $p$ value $=0.000$ & \\
\hline Experience & -0.123 & -2.225 & 0.027 & & \\
\hline Grade & -0.078 & -1.853 & 0.065 & & \\
\hline
\end{tabular}

${ }^{a}$ Dependent variable: PME: $r=$ correlation coefficient (standardized values): $\mathrm{n}=$ significant: $\mathrm{ns}=$ not significant

b Predictors: political support, stakeholder participation

c Predictors: stakeholder participation

d Predictors: stakeholder participation, age range, sex education, assembly size, grade, experience

e $N=424$

experience, and grade which were negatively associated with PME, three variables: age, assembly size and sex were positive. However, except for education which is not statistically significant, the rest of the control variables (age, sex, grade, experience, and assembly size) were statistically significant.

Regression Model 1(a) with PEREV as a dependent variable In this section, two models were run to test the relationship between the two organizational environment antecedents and PEREV. The results showed that the first model provided $26.6 \%$ with $F(2,419)=75.938, p=0.000$ when both variables were entered without control variables. For this model, correlation coefficients showed that STAKHOP contributed more to the changes in PEREV 
and was statistically significant at $0.01 \%(r=0.421, n)$, and POLSP contributed less but significant at $0.01 \%$ $(r=0.174, n)$, whereas the second model depicted that STAKHOP predicted the PEREV better with $(r=412$, $n)$ reducing by 0.009 points while POLSP predicted with $(r=0.171, n)$. The indication is that the first model is a good fit for the data without the control variables, though the model with control variables looks better. The behavior of the control variables showed that age, sex, education, and grade were negatively related to PEREV, which means any unit change in the independent variables led to a unit decrease in the dependent variable. In terms of statistical significance, sex was statistically significant at $p<0.001(p=0.005)$ (see Table 8). However, the second model was able to explain the variance of $28.2 \%$ which is 0.016 better than the 1 st model with $F(8,413)=20.227$, $p=0.000$.

\section{Regression Model 2 with PM as a dependent variable}

The variables for this model included PM (dependent variable), STAKHOP, and POLSP as independent variables, while age, sex, education, assembly size, grade, and experience were controlled variables. The model shows that the first regression results with POLSP and STAKHOP

Table 8 Regression results with PEREV as a dependent variable

\begin{tabular}{|c|c|c|c|c|c|}
\hline Model & $B$ & T-STAT & $p$ value & $\begin{array}{l}\text { Summary } \\
\text { statistics }\end{array}$ & Prediction \\
\hline 1 & & & & $R=0.516$ & \\
\hline (Constant) & 2.003 & 8.105 & 0.000 & $R^{2}=0.266$ & \\
\hline STAKHOP & 0.421 & 9.206 & 0.000 & $\begin{array}{l}\text { Adjusted } \\
R^{2}=0.263\end{array}$ & \\
\hline \multirow[t]{3}{*}{ POLSP } & 0.174 & 3.817 & 0.000 & S.E. $=0.98435$ & \\
\hline & & & & F stat $=75.938$ & \\
\hline & & & & $p$ value $=0.000$ & \\
\hline \multicolumn{6}{|l|}{2} \\
\hline (Constant) & 1.644 & 4.343 & 0.000 & $R=0.531$ & \\
\hline STAKHOP & 0.412 & 8.999 & 0.000 & $R^{2}=0.282$ & \\
\hline POLSP & 0.171 & 3.687 & 0.000 & $\begin{array}{l}\text { Adjusted } \\
\qquad R^{2}=0.268\end{array}$ & \\
\hline Age range & -0.020 & -0.360 & 0.719 & S.E. $=0.98097$ & \\
\hline Sex & 0.119 & 2.803 & 0.005 & F stat $=20.227$ & \\
\hline Education & -0.016 & -0.343 & 0.732 & $p$ value $=0.000$ & \\
\hline Assembly Size & 0.021 & 0.501 & 0.617 & & \\
\hline Experience & 0.053 & 0.959 & 0.338 & & \\
\hline Grade & -0.016 & -0.385 & 0.700 & & \\
\hline
\end{tabular}

a Predictors: political support, stakeholder participation

b Predictors: POLSP (political support), STAKHOP (stakeholder participation), grade, assembly size, sex, education, experience, age range

c Dependent variable: PEREV (performance review): $r=$ correlation coefficient (standardized values): $\mathrm{n}=$ significant: $\mathrm{ns}=$ not significant

d $N=424$ as predictors, the model contributed $27.6 \%$ with $F(2$, $423)=80.735, p=0.000$. For the correlation coefficients, the beta values showed that STAKHOP was positive and statistically significant at $(r=0.466, p=0.000)$, followed by POLSP with $(r=0.119, p=0.009)$. While the results for the controlled model showed that the 8 variables provided $31.3 \%$ variance with $F(8,417)=23.743, p=0.000$ in the dependent variable (PM), POLSP $(r=0.130, p<0.05)$ and STAKHOP $(r=0.454, p<0.001)$ best predicted the model. A closer look at the control variables showed that age, sex, and assembly size were statistically significant at $p<0.05$ and $p<0.01$ respectively. While education, experience, and grade were negatively related to $\mathrm{PM}$ and not significant (see Table 9). It means that the number of years on the job and whether you had a higher degree or not did not have any changes in the PM of the assembly. The indication is that grade, experience and education also decrease the PM of LGs as the results in this sample suggest. However, age, sex, and assembly size showed that these variables are important in the PM of LGs. Also, consistently, the results for the first and second regression models showed that STAKHOP predicted PM better than POLSP.

Table 9 Regression results with PM as a dependent variable

\begin{tabular}{|c|c|c|c|c|c|}
\hline Model & B & T-STAT & $p$ value & $\begin{array}{l}\text { Summary } \\
\text { Statistics }\end{array}$ & Prediction \\
\hline 1 & & & & $R=0.526$ & \\
\hline (Constant) & 2.697 & 12.586 & 0.000 & $R^{2}=0.276$ & \\
\hline STAKHOP & 0.466 & 10.330 & 0.000 & $\begin{array}{l}\text { Adjusted } \\
R^{2}=0.273\end{array}$ & \\
\hline \multirow[t]{3}{*}{ POLSP } & 0.119 & 2.636 & 0.009 & S.E. $=0.86004$ & \\
\hline & & & & F stat $=80.735$ & \\
\hline & & & & $p$ value $=0.000$ & \\
\hline \multicolumn{6}{|l|}{2} \\
\hline (Constant) & 1.895 & 5.868 & 0.000 & $R=0.559$ & \\
\hline STAKHOP & 0.454 & 10.180 & 0.000 & $R^{2}=0.313$ & \\
\hline POLSP & 0.130 & 2.889 & 0.004 & $\begin{array}{l}\text { Adjusted } \\
R^{2}=0.300\end{array}$ & \\
\hline Age range & 0.130 & 2.399 & 0.017 & S.E. $=0.84397$ & \\
\hline Sex & 0.135 & 2.270 & 0.001 & F stat $=23.743$ & \\
\hline Education & -0.02 & -0.464 & 0.643 & $p$ value $=0.000$ & \\
\hline Assembly size & 0.070 & 1.688 & 0.092 & & \\
\hline Experience & -0.034 & -0.635 & 0.526 & & \\
\hline Grade & -0.055 & -1.326 & 0.186 & & \\
\hline
\end{tabular}

a Predictors: STAKHOP (stakeholder participation), POLSP (political support)

b Predictors: POLSP, STAKHOP, education, assembly size, sex, grade, age range, experience

c Dependent variable: PM, $r=$ correlation coefficient (standardized values): $\mathrm{n}=$ significant: $\mathrm{ns}=$ not significant;

${ }^{d} N=424$ 


\section{Regression Model 3 relationship between PM and ORGENANTE}

The third regression model which is the main model of the study was to test the combined effect of the two organizational environment antecedents as a single independent variable: ORGENANTE on PM as a single dependent variable. Two models were run and the results indicate that the first model's total effect was significant with ORGENANTE contributing 27.5\% to explain the total variance in the dependent variable with $F(1,422)=128.079, p=0.000$. The correlation coefficients for the variable: ORGENVANTE had values of $(r=0.478, n)$. In the second model, the effect was $31.3 \%$ of the variance in PM with $F(7,426)=23.045$, $p=0.000$ when the control variables were introduced. Regarding the beta weights, ORGENANTE improved by 0.003 points $(r=0.481, n)$ while the control variables, sex, age, and assembly size were positive whereas, education, experience, and grade were negatively related to PM. However, only age $(r=0.14, p<0.001)$, sex $(r=0.145, p=0.001)$, and assembly size $(r=0.092$, $p<0.05)$ were statistically significant (see Table 10).

The study also tested for the multicollinearity, using the Tolerance values in Table 10, and a close examination of the results showed that the values range from 0.984 to 0.564 which is higher than a 0.10 to 1 requirement in social research [49]. Also, the Variance Inflation Factor (VIF) recommends that variables whose values are higher than 10 should not be excluded in the regression model when this occurs. However, the values in this study were far less than 10 and hence were not affected because most of the variables had VIF values of 1.774 to 1.017 . Also, the multi-collinearity test used the Durbin Watson test to check for serial correlation, and the value of the model is 1.867 which falls between the 1.50 and 2.50 cut-off points in social science research. The Durbin Watson test indicates that the residuals are

Table 10 Regression results of the relationship between PM and ORGENANTE

\begin{tabular}{|c|c|c|c|c|c|c|}
\hline \multirow[t]{2}{*}{ Model } & \multirow[t]{2}{*}{ B } & \multirow[t]{2}{*}{ T-STAT } & \multirow[t]{2}{*}{$p$ value } & \multirow[t]{2}{*}{ Summary statistics } & \multicolumn{2}{|c|}{ Collinearity statistics } \\
\hline & & & & & Tolerance & VIF \\
\hline 1 & & & & & 1.000 & 1.000 \\
\hline (Constant) & 2.837 & 13.102 & 0.000 & & & \\
\hline \multirow[t]{7}{*}{ ORGENANTE } & 0.478 & 11.317 & & & & \\
\hline & & & & $R=0.478$ & & \\
\hline & & & & $R^{2}=0.275$ & & \\
\hline & & & & Adjusted $R^{2}=0.227$ & & \\
\hline & & & & S.E. $=0.88249$ & & \\
\hline & & & & F stat $=128.079$ & & \\
\hline & & & & $p$ value $=0.000$ & & \\
\hline \multicolumn{7}{|l|}{2} \\
\hline (Constant) & 1.867 & 5.714 & 0.000 & & & \\
\hline ORGENANTE & 0.481 & 11.549 & 0.000 & & 0.984 & 1.017 \\
\hline Age range & 0.141 & 2.572 & 0.010 & & 0.568 & 1.761 \\
\hline Sex & 0.145 & 3.466 & 0.001 & & 0.973 & 1.028 \\
\hline Education & -0.026 & -0.593 & 0.553 & & 0.864 & 1.158 \\
\hline Assembly size & 0.092 & 2.188 & 0.029 & & 0.971 & 1.03 \\
\hline Experience & -0.024 & -0.443 & 0.658 & & 0.564 & 1.774 \\
\hline \multirow[t]{7}{*}{ Grade } & -0.052 & -1.226 & 0.221 & & 0.961 & 1.041 \\
\hline & & & & $R=0.524$ & & \\
\hline & & & & $R^{2}=0.313$ & & \\
\hline & & & & Adjusted $R^{2}=0.263$ & & \\
\hline & & & & S.E. $=0.86176$ & & \\
\hline & & & & F stat $=23.045$ & & \\
\hline & & & & $p$ value $=0.000$ & & \\
\hline
\end{tabular}

\footnotetext{
a Predictors: ORGENANTE (organizational environment antecedents)

b Predictors: ORGENANTE, experience, assembly size, grade, sex, education, age range

c Dependent variable: total PM; $r=$ correlation coefficient (standardized values): $\mathrm{n}=$ significant: $\mathrm{ns}=$ not significant

d $N=424$
} 
not correlated, given that the value is close to 2 . Therefore, the decision was made to retain all the variables in the main model to further test the hypotheses.

Furthermore, since the first two model results showed that the two variables have some level of effect on the two dimensions of the dependent variable, they will be retained in the hypotheses testing. Table 11 depicts the summary of the results of the multiple regression analysis and the outcomes of the hypotheses testing. The standard regression results are used to test the proposed hypotheses for the model's sub-hypotheses while the controlled effect is used to test the main hypothesis. There is one main hypothesis and six sub-hypotheses (see Table 11).

In Table 11, the main hypothesis (H1) and five of the sub-hypotheses (H1a, H1b, H1c, H1d, and H1e) were supported at a $p \leq 0.01$ significant level, while H1f was not supported. For organizational environment variables, STAKHOP predicted the combined weight of the two dimensions of PM better than the individual dimensions. Additionally, POLSP predicted moderately on PEREV and PM than it did on PME. The model of the study is revised in Fig. 2.

The study sought to test the effect of organizational environment antecedents on PM using two dimensions of the concept: PME and PEREV both as a single independent variable and a combined independent variable. The two variables demonstrated that there is a strong relationship between the antecedents of the organizational environment and PM. Even more, STAKHOP strongly predicted both PME and PEREV, which may be influenced by the fact that MMDAs are rated on the Functional Organizational Assessments Teams (FOAT) which is used to disburse the District Development Capacity Facility (DDF) fund. As part of the FOAT minimum conditions, stakeholder consultation in the budgeting and planning process is mandatory.

Table 11 Hypotheses results

\begin{tabular}{llllll}
\hline Hypothesis & $\begin{array}{l}\text { Predicted } \\
\text { relationship }\end{array}$ & Estimate & T-stat & $\boldsymbol{p}$ value & Outcome \\
\hline $\mathrm{H} 1$ & ENVIROND $\rightarrow$ PM & $0.481^{* * *}$ & 11.317 & 0.000 & $\mathrm{~S}$ \\
$\mathrm{H} 1 \mathrm{a}$ & $\mathrm{STAKHOP} \rightarrow \mathrm{PM}$ & $0.466^{* * *}$ & 10.330 & 0.000 & $\mathrm{~S}$ \\
$\mathrm{H} 1 \mathrm{~b}$ & $\mathrm{STAKHOP} \rightarrow \mathrm{PME}$ & $0.438^{* * *}$ & 9.230 & 0.000 & $\mathrm{~S}$ \\
$\mathrm{H} 1 \mathrm{C}$ & $\mathrm{STAK}-$ & $0.421^{* * *}$ & 9.206 & 0.000 & $\mathrm{~S}$ \\
& $\mathrm{HOP} \rightarrow$ PEREV & & & & \\
$\mathrm{H} 1 \mathrm{~d}$ & $\mathrm{POLSP} \rightarrow$ PM & $0.119^{* * *}$ & 2.636 & 0.009 & $\mathrm{~S}$ \\
$\mathrm{H} 1 \mathrm{e}$ & POLSP $\rightarrow$ PEREV & $0.174^{* * *}$ & 3.817 & 0.000 & $\mathrm{~S}$ \\
$\mathrm{H} 1 \mathrm{f}$ & POLSP $\rightarrow$ PEREV & 0.042 & 0.881 & 0.379 & $\mathrm{NS}$ \\
\end{tabular}

${ }_{* * * *}=0.01 \%,{ }^{* *}=0.05 \%$; the coefficients are standardized beta values $S$ supported, NS not supported
From the Standard regression models, it is evident that the organizational environment antecedents are good predictors of PM with moderate effects. However, the introduction of control variables saw a few point-changes in the regression weights of the two antecedents. This implied that organizational environment antecedents enhance PM, however, STAKHOP contributes more in explaining the effect size PM than POLSP [63]. Besides, three of the six control variables, age, sex, and assembly size were consistent in predicting the changes in the dependent variable. This finding is similar to Taylor and Taylor [58] where organizational size had a significant impact on PM.

Also, POLSP though having a positive relationship with $\mathrm{PM}$, its effect size is less and this confirms the evidence from previous literature that its contribution to PM effectiveness is weak $[52,63]$. The inference is that to ensure significant contributions of outside actors, like clients, inter-sectorial collaborators, and elected officials who are not directly involved in the day-to-day administration of the district assemblies, organizational leaders must engage in broader consultation to include them in the PM process.

This finding further confirms Bouckaert and Halligan's [10] and Yang and Hsieh's [63] studies that STAKHOP has a significant effect on 'performance measurement and management'. This study finds evidence to support that STAKHOP has a significant effect on two key dimensions of PM. The departure of this study with other findings on this variable is that the study systematically mapped different dimensions of PM and the empirical results demonstrate that stakeholders' involvement in the management process of MMDAs impacted significantly on their PME and PEREV put in place. Thus, organizations that engage others in the PM process tend to have a better review of their key performance areas (KPAs) and indicators.

Further, the hypothesis testing indicates that POLSP has a significant and positive effect on PM (see Table 11) and PEREV at $p<0.001$ level. This means that MMDAs who had the support of their elected officials (Assembly Members and Members of Parliament) or the district chief executives, were more likely to have positive outcomes on their PEREV process than those without the support of their elected officials.

The findings further suggest that contingent variables such as age, and gender, size are important in the outcomes of some of the dimensions of PM while other contingent factors such as education, experience, and grade may not contribute any change to the PM process. This is in line with the SCT that holds the view that some environmental situations may affect the performance of organizations if they are not well managed. 


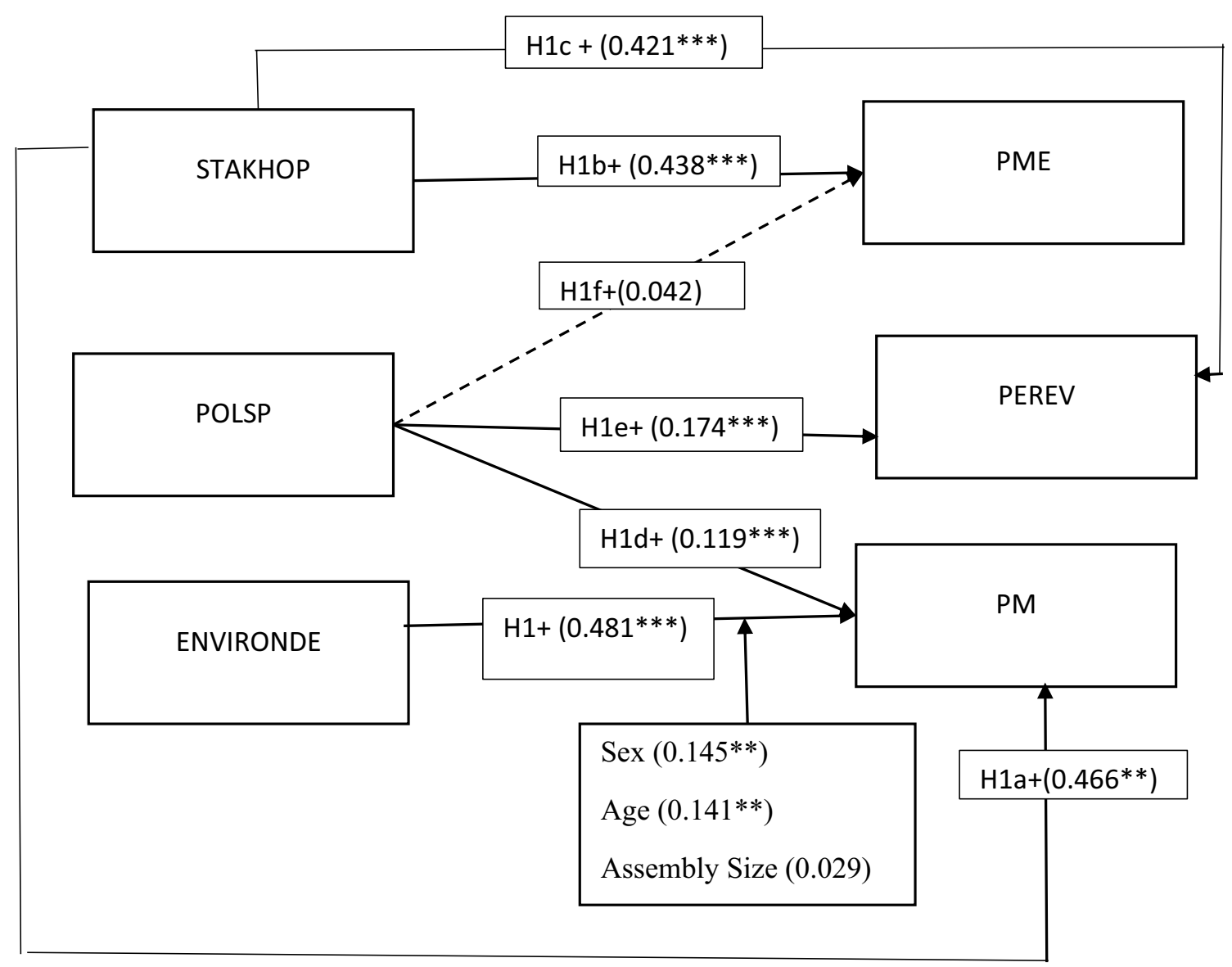

Fig. 2 Revised framework of performance management

Also, the participation of citizens and customers in the PM process, though an overlook area, may have 'spillover effects' on performance goals [30]. Fundamentally, LGs must ensure that key stakeholders participate in the implementation of PM policies by organizing Town Hall meetings and fora for active citizen participation in the development of the KPAs of the MMDAs because the KPAs are carved around the priority areas of the district's concern. The implications of these findings to the context of Ghana suggest that the involvement of key stakeholders such as elected officials and public managers should be reinforced for better outcomes on the PM policy goals in the local government. Also, it is important to foster a collaborative strategy on ways to improve political actors' support to level-institutions to carry out their mandate since the country is managed through a decentralized governance system. Further, organizational managers should focus on the performance review process to track employees' KPIs by carrying out mid-year and annual reviews in the performance year.

\section{Conclusion}

The organizational environment antecedents consist of STAKHOP and POLSP. The findings of these two variables indicate that both variables have a positive and significant effect on PM in all three models. Although STAKHOP has more strong support in predicting PM and its sub-dimensions than POLSP, the latter has a positive and significant impact on PM as a single dependent variable. However, the hypothesis testing showed that H1f was not supported (POLSP and PME), while the rest of the five sub-hypotheses $(\mathrm{H} 1 \mathrm{a}, \mathrm{H} 1 \mathrm{~b}, \mathrm{H} 1 \mathrm{c}, \mathrm{H} 1 \mathrm{~d}$, and H1f) were all supported including the main model (H1-ORGENANTE and PM). 
Unlike STAKHOP, POLSP was only significant with one dimension of PM (PEREV) while its effect on PME was not statistically significant. This implies that MMDAs should focus on encouraging their elected officials to support them during the PME sessions because this activity demand availability of resources and budgetary support for MMDAs to organize monitoring programs for their staff to enhance both individual and organizational performance. MMDAs need to encourage and involve their General Assemblies especially the Sub-committee system of the District Assembly to attract quality support from elected officials because these officials represent their constituents whom the MMDAs derive their KPAs.

The study concludes that since all the hypotheses were supported in the three regression models except one, the rejection of this hypothesis should be interpreted with caution because when the organizational environment antecedents were run in the main model as a combined variable, the effect was statistically significant (see Table 10). This implies that POLSP is still relevant to the implementation of the monitoring and evaluation activities at the local level during the performance year. The underlying assumption of LGs is to give voice and participation to the grassroots. Therefore, involving key inter-sectoral actors, clients/customers, elected officials, and structures of the District Assembly System especially the Sub-Committees of the Local Government Administrative System is fundamental to the success of the PM goals.

The study makes significant contributions to knowledge because this study has shown that the SCT can be used to explain the relationship between organizational environment antecedents and their impact on PM. With the inclusion of STAKHOP and POLSP in the environmental component of the SCT, the study closes the gap between theory and practice because the early conception of the contingency approach left out several contingent variables. Besides contributing to the structural contingency, it widens the possible expansion of the multiple contingency views to include more variables.

It is instructive to state that the limitations do not invalidate the findings of this study. One of the limitations of this study is the issue of missing data. The completed questionnaires had missing data where respondents decided to answer some questions and left others. This problem was present because the study used the human resource (HR) managers for the data collection and the respondent deposited the answered questionnaires at their HR departments.

The study used a cross-sectional survey that involved collecting data at one point in time. The limitation is that there is no opportunity to cross-validate the information, unlike a longitudinal study which could be used to collect information from the same respondents at different times and compare them. Therefore, future studies could use both longitudinal and qualitative interviews to support a quantitative design.

\section{Abbreviations}

CSPIP: Civil Service Performance Improvement Program; CSRP: Civil Service Reform Program; ERP: Economic Reform Program; HR: human resource; KPAs: key performance areas; KPIs: key performance indicators; LG: Iocal government; LGs: local governments; LGS: Local Government Service; MMAs: metropolitan and municipal assemblies; MMDAs: metropolitan, municipal and district assemblies; ORGENANTE: organizational environment antecedents; POLSP: political support; PM: performance management; PMP: performance management practices; PME: performance monitoring and evaluation; PEREV: performance review; SAP: Structural Adjustment Program; SCT: structural contingency theory; STAKHOP: stakeholder participation; VIF: variance inflation factor.

\section{Acknowledgements}

Not applicable.

\section{Authors' contributions}

JAA performed the analysis and interpreted the regression results as well as the literature review, and was the major contributor in writing the manuscript. EB designed the soundness of the analysis and the literature. All authors read and approved the final manuscript.

\section{Funding}

There are no funding sources for this research paper.

\section{Availability of data and materials}

The datasets used and/or analysed during the current study are not publicly available due to the privacy of the participants who provided the information for the study but are available from the corresponding author on reasonable request.

\section{Competing interests}

The authors declare that they have no competing interests.

\section{Author details}

${ }^{1}$ University of Mines and Technology, Tarkwa, Ghana. ${ }^{2}$ Department of History and Political Studies, Kwame Nkrumah University of Science and Technology, Kumasi, Ghana.

\section{Appendix 1}

See Table 12. 
Table 12 Performance management construct

\begin{tabular}{|c|c|c|c|}
\hline Variable & Indicator & Scale & No. of items \\
\hline PM1 & PME & $\begin{array}{l}\text { PME1: The assembly's performance management involves formal assessment of individual employee perfor- } \\
\text { mance } \\
\text { PME2: Task performance is supervised by the boss regularly } \\
\text { PME3: Employees can track their progress on key performance indicators (KPIs) } \\
\text { PME4: The assembly has a routine monitoring plan of the assembly's performance } \\
\text { PME5: The overall performance of employees is rated and scored during mid-year and annual reviews }\end{array}$ & 5 \\
\hline PM2 & PEREV & $\begin{array}{l}\text { PEREV1: The results of my performance are communicated to me } \\
\text { PEREV2: The assembly uses quarterly reviews to provide progress on individual and organizational goals to } \\
\text { Staff and stakeholders } \\
\text { PEREV3: The assembly organizes performance review sessions } \\
\text { PEREV4: The assembly uses performance management information to give incentives to high performers } \\
\text { PEREV5: The assembly uses performance management information to promote satisfactory performance } \\
\text { PEREV: During performance reviews, supervisors focus on the results that subordinates should obtain } \\
\text { PEREV7: During performance reviews, supervisors focus on subordinates' personal development } \\
\text { PEREV8: During performance reviews, supervisors focus on what subordinates do and how they do their job }\end{array}$ & 8 \\
\hline Total PM & PME + PEREV & & $5+8=13$ \\
\hline
\end{tabular}

Appendix 2

See Table 13.
Received: 23 September 2020 Accepted: 7 December 2020

Published: 12 January 2021

Table 13 Organizational environment antecedents construct

\begin{tabular}{|c|c|c|}
\hline Variable & Sub-variable/indicator & Scale \\
\hline ORGENANTE 1 & STAKHOP & $\begin{array}{l}\text { STAKHOP1: Citizens participate in designing this assembly's performance } \\
\text { indicators } \\
\text { STAKHOP2: Elected officials participate in designing this assembly's } \\
\text { performance indicators } \\
\text { STAKHOP3: Citizens help this assembly to evaluate its performance } \\
\text { STAKHOP4: The assembly involves staff in designing performance indica- } \\
\text { tors } \\
\text { STAKHOP5: Assembly staff are part of the performance evaluation process } \\
\text { of this assembly } \\
\text { STAKHOP6: External stakeholders are familiar with the results of this } \\
\text { assembly's performance management goals } \\
\text { STAKHOP7: stakeholders trust the performance management system of } \\
\text { this assembly } \\
\text { STAKHOP8: This assembly's performance management helps communi- } \\
\text { cate more effectively with elected officials and citizens } \\
\text { STAKHOP9: Staff are actively part of this assembly's performance manage- } \\
\text { ment process } \\
\text { STAKHOP10: Senior management is committed to this assembly's perfor- } \\
\text { mance management goals } \\
\text { STAKHOP11: Staff are committed to this assembly's performance man- } \\
\text { agement policy }\end{array}$ \\
\hline ORGENANTE 2 & POLSP & $\begin{array}{l}\text { POLSP1: This assembly has a low level of autonomy granted by elected } \\
\text { officials } \\
\text { POLSP2: Compared with other MMAs, this assembly enjoys a high level } \\
\text { of authority } \\
\text { POLSP3: The policy initiative or request from my assembly is not always } \\
\text { supported by elected officials } \\
\text { POLSP4: Most elected officials in this district do not trust the assembly } \\
\text { POLSP5: Most elected officials are very critical of the assembly because } \\
\text { the assembly is less effective } \\
\text { POLSP6: Elected officials support my organization with enough resources } \\
\text { to implement training needs assessments of the assembly } \\
\text { POLSP7: Elected officials support my assembly with resources to imple- } \\
\text { ment performance management programs }\end{array}$ \\
\hline
\end{tabular}




\section{References}

1. Abane JA, Phinaitrup B (2017) Performance management as an alternative tool for local governance: evidence from Ghanaian local government sector. Int J Hum Resour Manag Stud 7(3):188-209. https://doi. org/10.5296/ijhrs.v7i3.11532

2. Adei S, Boachie-Danquah Y (2003) The civil service performance improvement programme (CSPIP) in Ghana: lessons of experience. Afr J Public Admin Manag 14(1):10-23

3. Ammons DN, Roenigk DJ (2015) Performance Management in Local Government: Is Practice Influenced by Doctrine? Public Perform Manag Rev 38(3):514-541. https://doi.org/10.1080/15309576.2015.1006461

4. Armstrong M, Baron A (1998) Performance management: the new realistic. Institute of Personnel and Development, USA

5. Ayee JRA (2001) Civil service reform in Ghana: a case study of contemporary reform problems in Africa. Afr J Polit Sci 6(1):1-41

6. Baker BO, Hardyck CD, Peterinovich LF (1966) Weak measurement vs. strong statistics: an empirical cirtique of S.S. Stevens' proscriptions on statistics. Educ Psychol Meas 26(2):291-309. https://doi.org/10.1177/00131 6446602600204

7. Biron M, Farndale E, Paauwe J (2011) Performance management effectiveness: lessons from world-leading firms. Int J Hum Resour Manag Stud 22(6):1294-1311. https://doi.org/10.1080/09585192.2011.559100

8. Blau PM (1970) A formal theory of differentiation in organizations. Am Sociol Rev 35(2):201-218

9. Boland T, Fowler A (2000) A systems perspective of performance management in public sector organizations. Int J Public Sect Manag 13(5):417-446. https://doi.org/10.1108/09513550010350832

10. Bouckaert G, Halligan J (2008) Managing performance: international comparisons. Routledge, New York

11. Bourne M, Neely A, Platts K, Mills J (2002) The success and failure of performance measurement initiatives perceptions of participating managers. Int J Oper Prod Manag 2211 (11):1288-1310. https://doi. org/10.1108/01443570210450329

12. Burns T, Stalker GM (1994) The management of Innovation. Oxford University Press, Cambridge

13. Cavalluzzo KS, Ittner CD (2004) Implementing performance measurement innovations: evidence from government. Acc Organ Soc 29(3-4):243-267. https://doi.org/10.1016/S0361-3682(03)00013-8

14. Chenhall RH (2005) Integrative strategic performance measurement systems, strategic alignment of manufacturing, learning and strategic outcomes: an exploratory study. Acc Organ Soc 30(5):395-422. https:// doi.org/10.1016/j.aos.2004.08.001

15. Christensen T, Lægreid P, Stigen IM (2006) Performance management and public sector reform: the Norwegian hospital reform. Int Public Manag J 9(2):113-139. https://doi.org/10.1080/10967490600766987

16. Conaty FJ (2012) Performance management challenges in hybrid NPO/ public sector settings: an Irish case. Int J Prod Perform Manag 61(3):290309. https://doi.org/10.1108/17410401211205650

17. De Lancer JP, Holzer M (2001) Promoting utilization of performance measures in public organizations: an empirical study of factors affecting adoption and implementation. Public Admin Dev 61(6):693-708. https:// doi.org/10.1111/0033-3352.00140

18. DeNisi AS (2011) Managing performance to change behavior. J Organ Behav Manag 31(4):262-276. https://doi.org/10.1080/01608 061.2011 .619414

19. Dewettinck K, van Dijk H (2013) Linking Belgian employee performance management system characteristics with performance management system effectiveness: exploring the mediating role of fairness. Int J Hum Resour Manag Stud 24(4):806-825. https://doi.org/10.1080/09585 192.2012.700169

20. Farneti F (2009) Balanced scorecard implementation in an Italian local government organization. Public Money Manag 29(5):313-320. https:// doi.org/10.1080/09540960903205964

21. Ferreira A, Otley D (2009) The design and use of performance management systems: an extended framework for analysis. Manag Account Res 20(4):263-282. https://doi.org/10.1016/j.mar.2009.07.003

22. Galbraith JR (1973) Designing complex organizations. Addison-Wesley Publishing, Reading

23. Gerrish $\mathrm{E}$ (2016) The impact of performance management on performance in public organizations: a meta-analysis. Public Admin Rev 76(1):48-66. https://doi.org/10.1111/puar.12433.48
24. Gianakis GA, Wang XG (2000) Decentralization of the purchasing function in municipal governments: a national survey. J Public Budget Account Financ Manag 12(3):421-440

25. Gruening G (2001) Origin and theoretical basis of new public management. Int Public Manag J 4:1-25. https://doi.org/10.1016/S1096 -7494(01)00041-1

26. Hatch MJ, Cunliffe AL (2012) Organization theory: modern, symbolic and postmodern perspectives, 3rd edn. Oxford University Press, Oxford

27. Hawke L (2012) Australian public sector performance management: success or stagnation? Int J Prod Perform Manag 61:310-328. https://doi. org/10.1108/17410401211205669

28. Kaplan RS, Norton DP (1996) The balanced scorecard: translating strategy into action. Harvard Business Press, Harvard

29. Kaplan RS, Norton DP (1992) The balanced scorecard-measures that drive performance the balanced scorecard-measures. Harvard Business Review, January-February, pp 71-79

30. Kroll A, Neshkova MI, Pandey SK (2017) Spillover effects from customer to citizen orientation: how performance management reforms can foster public participation. Admin Soc. https://doi.org/10.1177/0095399716 687341

31. Kuvaas B, Buch R, Dysvik A (2016) Performance management: perceiving goals as invariable and implications for perceived job autonomy and performance. Hum Resour Manag 55(3):401-412

32. Labovitz SI (1967) Interaction effects and research design. Sociol Inq 37(2):341-344. https://doi.org/10.1111/j.1475-682X.1967.tb00664.x

33. Latham GP, Borgogni L, Petitta L (2008) Goal setting and performance management in the public sector. Int Public Manag J 11(4):385-403. https://doi.org/10.1080/10967490802491087

34. Lee CD (2005) Rethinking the goals of your performance-management system. Employ Relat Today Wiley 32(3):53-60. https://doi.org/10.1002/ ert.20075

35. Maley J (2014) Sustainability: the missing element in performance management. Asia Pac J Bus Admin 6(3):190-205. https://doi.org/10.1108/ APJBA-03-2014-0040

36. Mintzberg H (1980) Structure in 5'S: a synthesis of the research on organization design. Manag Sci 26(3):322-341. https://doi.org/10.1287/ mnsc.26.3.322

37. Mintzberg H (1993) Structure in fives: designing effective organizations. Prentice-Hall, Upper Saddle River

38. Moynihan DP, Pandey SK (2005) Testing how management matters in an era of government by performance management. J Public Admin Res Theory 15(3):421-439. https://doi.org/10.1093/jopart/mui016

39. Moynihan DP, Pandey SK (2010) The big question for performance management: why do managers use performance information? J Public Admin Res Theory 20(4):849-866. https://doi.org/10.1093/jopart/muq004

40. Newcomer KE (2007) Measuring government performance. Int J Public Admin 30(3):307-329. https://doi.org/10.1080/01900690601117804

41. Nudurupati SS, Tebboune S, Hardman J (2016) Contemporary performance measurement and management (PMM) in digital economies. Prod Plan Control 27(3):226-235. https://doi.org/10.1080/09537 287.2015 .1092611

42. Mohamad MHS, Ismail S (2014) The effect of regulation and goal orientation on performance measurement utilisation: evidence from Indonesian local governments. Asian J Bus Account 7(1):81-105

43. O'Boyle I, Hassan D (2013) Organizational performance management: examining the practical utility of the performance prism. Organ Dev J 31(3):51-58

44. Ohemeng FLK (2009) Constraints in the implementation of performance management systems in developing countries: the Ghanaian case. Int J Cross Cult Manag 9(1):109-132. https://doi.org/10.1177/1470595808 101158

45. Ohemeng FL (2011) Institutionalizing the performance management system in public organizations in Ghana. Public Perform Manag Rev 34(4):467-488. https://doi.org/10.2753/PMR1530-9576340402

46. Ohemeng FK, Anebo FK (2012) The politics of administrative reforms in Ghana: perspectives from path dependency and punctuated equilibrium theories. Int J Public Admin 35(3):161-176. https://doi.org/10.1080/01900 692.2011.635470

47. Oliver C (1991) Strategic responses to institutional processes. Source Acad Manag Rev 16(1):145-179. https://doi.org/10.5465/AMR.1991.42790 
48. Otley D (1999) Performance management: a framework for management control systems research. Manag Account Res 10(4):363-382. https://doi. org/10.1006/mare.1999.0115

49. Pallant J (2011) SPSS survival manual: a step by step guide to data analysis using SPSS, 4th edn. Allen \& Unwin, New York

50. Perry JL (1996) Measuring public service motivation: an assessment of construct reliability and validity. J Public Admin Res Theory 6(1):5-22. https://doi.org/10.1093/oxfordjournals.jpart.a024303

51. Pfeffer JL (1982) Organizations and organization theory. Pitman, New York

52. Pollitt C, Bouckaert G (2004) Public management reform: a comparative analysis. Oxford University Press, Oxford

53. Public Services Commission (2012) Performance Management Policy for the Public Services of Ghana. PSC Printing Press, Accra

54. Pugh DS, Hickson DJ, Hinings CR (1969) An empirical taxonomy of structures of work organizations. Admin Sci Q 14:115-126

55. Rainey H, Steinbauer P (1999) Galloping elephants: developing elements of a theory of effective government organizations. J Public Admin Res Theory 9:1-32

56. Rhodes ML, Biondi L, Gomes R, Melo Al, Ohemeng F, Perez-Lopez G, Rossi A, Sutiyono W (2012) Current state of public sector performance management in seven selected countries. Int J Prod Perform Manage 61(3):235-271. https://doi.org/10.1108/17410401211205632
57. Sanderson I (2001) Performance management, evaluation and learning in 'modern' local government. Public Admin 79(2):297-313. https://doi. org/10.1111/1467-9299.00257

58. Taylor A, Taylor M (2014) Factors influencing effective implementation of performance measurement systems in small and medium-sized enterprises and large firms: a perspective from contingency theory. Int J Prod Res 52(3):847-866. https://doi.org/10.1080/00207543.2013.842023

59. The United Nations Development Programme (2019) Inequalities in human development in the 21st century. UN Publications, Washington

60. Thompson FJ, Ricucci NM (1998) Reinventing government. Ann Rev Polit Sci 1:231-257

61. Toppo L, Prusty T (2012) From performance appraisal to performance management. J Bus Manag 3(5):1-6

62. Weber M (1947) The theory of economic and social organizations. In: Henderson TFL, Parsons AM (ed). Oxford University Press, Oxford

63. Yang K, Hsieh JY (2007) Managerial effectiveness of government performance measurement: testing a middle-range model. Public Admin Rev $67: 861-879$

\section{Submit your manuscript to a SpringerOpen ${ }^{\odot}$ journal and benefit from:}

- Convenient online submission

- Rigorous peer review

- Open access: articles freely available online

- High visibility within the field

- Retaining the copyright to your article

Submit your next manuscript at $\boldsymbol{\nabla}$ springeropen.com 